\title{
The alternate-day fasting diet is a more effective approach than a calorie restriction diet on weight loss and hs-CRP levels
}

\author{
Roghaye Razavi ${ }^{1}$, Arefe Parvaresh ${ }^{1}$, Behnood Abbasi \\ Khadijeh Yaghoobloo ${ }^{1}$, Akbar Hassanzadeh ${ }^{3}$, Noushin Mohammadifard ${ }^{4}$ \\ Cain C. T. Clark ${ }^{5}$, and Sayyed Morteza Safavi ${ }^{1}$

\begin{abstract}
Department of Clinical Nutrition, School of Nutrition and Food Science, Isfahan University of Medical Science, Isfahan, Iran
2 Assistant Professor of Nutrition, Department of Nutrition, Science and Research Branch, Islamic Azad University, Tehran, Iran
\end{abstract} \\ 3 Department of epidemiology and biostatistics, School of health, Isfahan University of Medical Science, Isfahan, Iran \\ 4 Isfahan Cardiovascular Research Center, Cardiovascular Research Institute, Isfahan University of Medical Science, Isfahan, Iran \\ 5 Faculty Research Centre for Sport, Exercise and Life Sciences, Coventry University, Coventry, UK
}

\begin{abstract}
Background and Objective: The aim of present study was to compare, and determine, the effects of a modified alternate-day fasting diet vs. calorie restriction on inflammatory indices and coagulation factors. Methods: This was a randomized clinical trial consisting of 80 metabolic syndrome patients, who were enrolled and randomly dichotomized into a modified alternate-day fasting diet or calorie restriction group for 4 months. We measured weight, body mass index (BMI), waist circumstance (WC), waist-hip-ratio (WHR) and fat mass as primary outcomes and assessed high sensitivity C-reactive protein (hs-CRP), interleukin 6 (IL-6), tumor necrosis factor alpha (TNF- $\alpha$ ) and coagulation factors levels as secondary outcomes before and after intervention. Results: Compared to the calorie restriction diet, following a modified alternate-day fasting diet led to a greater reduction in body weight $(\mathrm{kg})(-6.43 \pm 4.34 \mathrm{vs}-4.11 \pm 4.27 ; \mathrm{P}=0.02), \mathrm{BMl}\left(\mathrm{kg} / \mathrm{m}^{2}\right)(-3.19 \pm 2.90 \mathrm{vs}-$ $1.43 \pm 2.72 ; P=0.01)$, fat mass $(\mathrm{kg})(-4.88 \pm 2.09$ vs $-3.72 \pm 2.43 ; P=0.03)$, WC $(\mathrm{cm})(-5.57 \pm 5.64$ vs $-2.32 \pm 5.95 ; P=0.01)$ and $W H R$ $(-0.05 \pm 0.06$ vs $-0.02 \pm 0.07 ; P=0.04)$. Furthermore, a greater change was found in hs-CRP levels $(\mathrm{mg} / \mathrm{L})(-2.06 \pm 1.18 \mathrm{vs}-0.97 \pm 0.82 ;$ $P=0.03)$, prothrombin time (s) $(1.41 \pm 2.34 \mathrm{vs}-0.41 \pm 2.17 ; \mathrm{P}<0.001)$, activated partial thromboplastin time (s) $(0.26 \pm 3.70 \mathrm{vs}-1.78 \pm 3.56$; $\mathrm{P}=0.04)$ in modified alternate-day fasting diet when compared to calorie restriction diet. However, there was no difference in TNF- $\alpha$ or IL-6 and fibrinogen between groups $(P>0.05)$. Conclusions: These findings suggest that a modified alternate-day fasting diet can be a beneficial alternative for the management of body weight, fat mass and WC as well as hs-CRP and coagulation factors levels among metabolic syndrome patients.
\end{abstract}

Keywords: Alternate-day fasting diet, energy restriction, inflammation, metabolic syndrome

\section{Introduction}

Metabolic syndrome (MetS) is characterized by a cluster of interconnected biochemical, clinical, physiological and metabolic factors, leading to an increased risk of type 2 diabetes mellitus, cardiovascular disease, and all-cause mortality $[1,2]$. Insulin resistance, elevated blood pressure, abdominal obesity, endothelial dysfunction, atherogenic dyslipidemia, chronic stress and genetic susceptibility are the most preponderant risk factors contributing to MetS [3]. Due to an inexorably rising prevalence, MetS is regarded an important worldwide health problem and represents a large burden on healthcare systems and resource utilization $[2,4]$. It has been suggested that excess consumption of high-calorie food and having a sedentary lifestyle are the most common cause of developing, and indeed progression, of MetS [5]. Several empirical studies have shown that obesity is connected with an increased production of inflammatory cytokines, which can facilitate the progression of insulin resistance [6-8]. In addition, there is an association between obesity and high levels of various coagulation factors, such as coagulation factor $\mathrm{X}$ (fibrinogen) levels, which is a common risk factor for stroke or Coronary Heart Disease (CHD) [9]. Thus, a reduction in energy intake might, conceivably, have a key role in the treatment of MetS, and, consequently, in 
reducing the risk of cardiovascular disease via mitigation of inflammatory index and coagulation factors in overweight and obese populations [10].

A daily calorie restriction (CR) diet has been used as common strategy for weight loss; where such regimens require decreasing energy intake by 15 to $40 \%$ of baseline needs every day, whilst retaining sufficient nutrient intake [10]. Although CR is efficiacious for weight loss in obese individuals, many people recognize it difficult to adhere to these diets [11]. Another dietary strategy, that may be more feasible in practice than daily $\mathrm{CR}$, is an alternate day fasting (ADF) regimen, which consists of a "fast day", where intake is limited to $25 \%$ of the individual's energy needs, (approximately 500 calories) alternating with a "feed day", where food is consumed ad-libitum (ad libitum food consumption) [12]. The positive effect of ADF diet on weight and visceral fat mass loss among overweight adults have previously been demonstrated [13]. However, there is currently insufficient information in this strategy among MetS patients. As urbanization advances, concomitant to highcalorie food consumption and sedentary lifestyle induced obesity, presenting a more practical approach to prevent and/or control MetS remains as a critical challenge faced by healthcare systems, globally. Therefore, the present study was conducted to investigate the impact of ADF versus $C R$ diet on inflammatory index and coagulation factors in patients with MetS.

\section{Method}

\section{Study participants}

The current study was a single-center, randomized clinical trial. The experimental protocol was approved by the research ethics committee of the Isfahan University of Medical Sciences, Isfahan - Iran (IR.MUI. REC.1394.3.892). The study was performed in accord with the CONSORT statement recommendation [14]. Patients were identified and recruited from Sediqe-Tahere Heart Center between December 2015 and May 2016. MetS was diagnosed according to The Revised National Cholesterol Education Program Third Adult Treatment Panel (RNCEP: ATPIII) definition [15]. The key criteria for inclusion were patients with MetS confirmed by a specialist, age 25-60 years, and $25 \leq$ body mass index (BMI) $\leq 40 \mathrm{~kg} / \mathrm{m}^{2}$. Subjects were excluded from the study if they had weight changes $\geq 5 \%$ for 3 months prior to the study, history of cardiovascular, renal, liver and metabolic disease, smoking or taking any medication in last 6 months which is known to impact on weight loss, inflammatory status and coagulation factors, following especial diet, breast feeding, post-menopausal or pregnant women. Sample size was calculated using the formula suggested for randomized clinical based on type one error $(\alpha)=0.05$ and power $=$ $0.80 \%$. Considering $20 \%$ drop-out, the final sample size was 40 participants per group.

\section{Study design}

A total of 80 individuals with MetS were eligible and entered in to the two-week run in period. Firstly, written informed consent was obtained from all participants after explanation of the goal and nature of the trial. Then, all participants were stratified for BMI, age and sex, and were randomly assigned to ADF or CR group for 4 months. Randomization was performed using by random-generation software. The participants were instructed to complete a personal, socioeconomic information and medical/health history questionnaire accompanied by a well-trained staff member at the start of the study. All subjects were informed to maintain their regular physical activity habits through the time of investigation, and not to consume any supplements and/or medications which might affect related markers. Participants were also asked to complete a physical activity and 3-days dietary record (over two weekdays and one weekend day) to determine compliance with the study's dietary goals. In addition, the participant's adherence with the respective diets was monitored by phone interviews during the week.

\section{Diet protocol}

All patients were instructed to adhere to a personally prescribed diet. During the 4 months ADF period, subjects consumed a very low-calorie diet (75\% energy restriction) during the 3 fast days (Saturday, Monday, Wednesday) and then consumed ad libitum without limitation on each feed day (4 days a week). ADF subjects were provided with meals on each fast day (ranging from $400-600 \mathrm{kcal}$ ), and consumed ad libitum at home on the feed day. The feed and fast days began at midnight each day, and all fast day meals were consumed between $12.00 \mathrm{pm}$ and $2.00 \mathrm{pm}$ to ensure that each subject was undergoing the same duration of fasting. Subjects were permitted to consume caloriefree foods such as water, tea, green tea, coffee without sugar ( $<400 \mathrm{mg}$ caffeine per day), non-starchy vegetable (such as lettuce, cucumber, green leaf, tomato) and sugar-free gums on a fast day and were encouraged to drink plenty of water. In the CR group, the baseline energy requirements for the subjects were assessed by Mifflin equation [16] and subjects consumed $75 \%$ energy needs each day. All subjects were required to prepare all of their meals at home, and were guided on how to make healthy food choices, by selecting low-fat meat and dairy options and increasing fruit and 
vegetable intake. Daily dietary carbohydrate, fat, and protein accounted for 52, 30 and $18 \%$ of ingested energy, respectively. The weekly schedule of dietary following is presented as Table E1 in Electronic Supplementary Material 1.

\section{Blood sampling and biochemical analyses}

A 10-milliliter fasting blood samples were drawn from each participant after a 12-h overnight fasting at pre and postintervention to assess serum high sensitivity-C-Reactive Protein (Hs-CRP), Prothrombin time (PT), activated limited thromboplastin time (a-PTT), and fibrinogen. All serums were also separated by centrifugation and were stored at $-70{ }^{\circ} \mathrm{C}$. The serum hs-CRP concentration was assayed by using ELISA kits (LDN, Nordhorn, Germany). Serum concentrations of interleukin-6 (IL-6) and tumor necrosis factor-alpha (TNF-a) were determined by the enzyme linked immunoassay technique with available commercial kits (Pars Azmoon. Co., Tabriz, Iran). Fibrinogen was also measured using immunoturbidimetry tests (Pars Azmoon. Co., Tabriz, Iran) according to the manufacturer's instructions. The Duke method was applied to measure bleeding time while a fingertip was pricked via lancet to cause bleeding. All measures were conducted by a technician who was blind to the assigned treatment to each patient.

Body weight was measured by scale (Seca Hamburg Germany) to the nearest $0.1 \mathrm{~kg}$ in light clothing, standing unshod in the first visit and after each month for 4 months. Fat mass was evaluated via bioimpedance analyzer (BIA; BC-418, Tanita Europe, Amsterdam, NL) with participants standing on metal foot-plates while holding the handles. BMI was calculated using the standard formula [body mass $(\mathrm{kg}) /$ height $\left(\mathrm{m}^{2}\right)$ ]. Waist circumstance (WC) was evaluated at the level of the umbilicus and waist-to-hip ratio (WHR) was determined by divided WC on the hip measured at its greatest gluteal protuberance.

\section{Primary and secondary outcomes}

The primary outcomes of the study were significant changes in body weight, BMI, fat mass, fat free mass, WC and WHR. The secondary outcome measurements included decreases in hs-CRP, TNF- $\alpha$, IL-6, PT, a-PTT and Fibrinogen levels among participants.

\section{Statistical analysis}

All statistical analyses were conducted by using Statistical Package for the Social Sciences (SPSS) software, version 21 (SPSS Inc, Chicago, IL, USA). Kolmogorov-Smirnov and Levene's test was used to check for normality distribution of data and equality of variances, respectively. A paired $t$-test was used to detect the differences between post intervention measurements from baseline values. Differences in bassline characteristics measured between ADF and $\mathrm{CR}$ diet groups were detected with independentsample $t$-tests or the Chi-square test with regard for the type of variables. Due to the comparison of changes between the 2 groups in primary and secondary outcomes, analysis of covariance (ANCOVA) test was applied while controlling for identified covariates. In addition, a repeated-measures ANCOVA was used for comparing the evolution of change in body weight, BMI, WC and WHR during the 4-months treatment among the 2 groups. Results are expressed as means \pm Standard Deviation (SD), and a P-value less than 0.05 was considered statistically significant.

\section{Results}

As demonstrated in the study flow diagram (Figure 1), a total 80 patients were eligible and were randomly assigned into the ADF and CR groups.

During the follow-up phase, 2 patients from AFD [over $10 \%$ discontinued intervention $(\mathrm{n}=2)$ ] and 3 patients from CR group [over 10\% discontinued intervention $(n=2)$ and migration $(n=1)]$ were excluded. Finally, 75 subjects completed the trial and were included in the final analysis. The number of dropouts did not differ between the study groups $(\mathrm{p}>0.05)$.

There were no significant differences between groups in term of anthropometric measures, blood pressure and physical activity (Table1).

Furthermore, the baseline dietary assessment based on 3-days dietary record was comparable in both groups (Table 2).

No adverse effects associated with following the diets were reported among participants in ADF or CR group throughout the trial.

\section{Primary outcomes}

After 4-months intervention, a greater, significant, reduction in body weight $(\mathrm{kg})(-6.43 \pm 4.34$ vs $-4.11 \pm 4.27$; $\mathrm{P}=0.02)$, BMI $\left(\mathrm{kg} / \mathrm{m}^{2}\right)(-3.19 \pm 2.90$ vs $-1.43 \pm 2.72 ;$ $\mathrm{P}=0.01)$, fat mass $(\mathrm{kg})(-5.88 \pm 3.84$ vs $-3.72 \pm 3.03$; $\mathrm{P}=0.007), \mathrm{WC}(\mathrm{cm})(-5.57 \pm 5.64$ vs $-2.32 \pm 5.95$; $\mathrm{P}=0.01)$ and WHR $(-0.05 \pm 0.06$ vs $-0.02 \pm 0.07$; $\mathrm{P}=0.04)$ was observed in ADF group in comparison to CR. No significant difference was observed in change of fat free mass $(\mathrm{kg})(-0.55 \pm 3.91$ vs $-0.39 \pm 3.17 ; \mathrm{P}=0.84)$ between 2 groups (Figure $2 \&$ Table 3 ). 


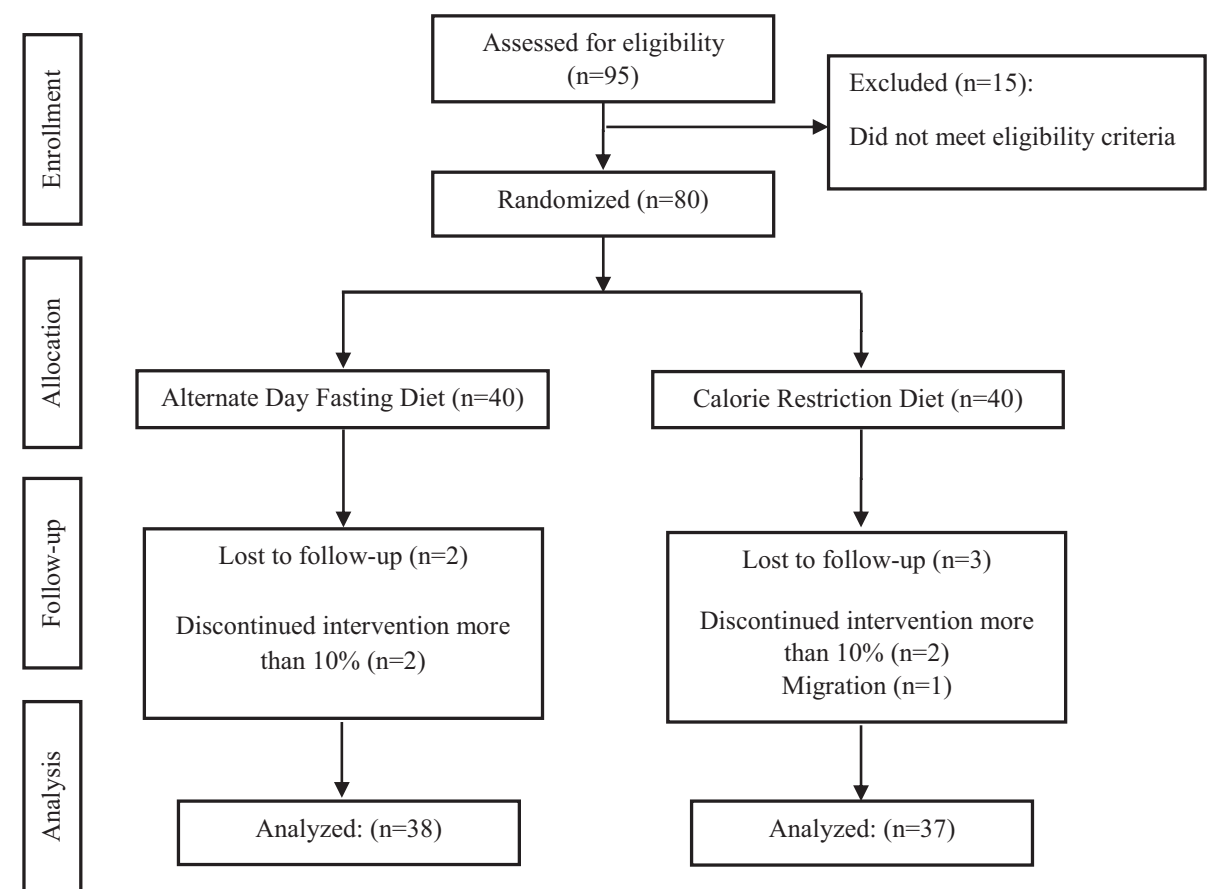

Figure 1. Summary of participant flow diagram.

Table 1. General characteristics of study participants

\begin{tabular}{|c|c|c|c|}
\hline Variables & ADF Diet group $(N=38)$ & CR group Diet $(N=37)$ & P-value \\
\hline Age (year) & $41.3 \pm 8.65$ & $43.1 \pm 9.26$ & 0.38 \\
\hline $\operatorname{Sex}(M / F)$ & $21 \mathrm{M} / 14 \mathrm{~F}$ & $20 \mathrm{M} / 14 \mathrm{~F}$ & 0.91 \\
\hline Body weight (kg) & $89.4 \pm 7.72$ & $87.1 \pm 8.17$ & 0.41 \\
\hline Fat mass (kg) & $37.1 \pm 9.25$ & $34.2 \pm 9.80$ & 0.21 \\
\hline Height $(\mathrm{cm})$ & $169 \pm 10$ & $168 \pm 12$ & 0.78 \\
\hline $\mathrm{BMI}\left(\mathrm{kg} / \mathrm{m}^{2}\right)$ & $31.3 \pm 3.12$ & $31.2 \pm 3.95$ & 0.85 \\
\hline Waist circumference & $106 \pm 9.71$ & $104 \pm 10.2$ & 0.23 \\
\hline Systolic blood pressure (mm Hg) & $134 \pm 9$ & $137 \pm 10$ & 0.33 \\
\hline Diastolic blood pressure $(\mathrm{mm} \mathrm{Hg})$ & $86 \pm 4$ & $85 \pm 5$ & 0.35 \\
\hline Physical activity (MET-h/day) at baseline & $32.8 \pm 6.21$ & $32.1 \pm 5.37$ & 0.61 \\
\hline Physical activity (MET-h/day) at end of trial & $33.7 \pm 5.81$ & $34.9 \pm 5.78$ & 0.38 \\
\hline
\end{tabular}

Values reported as mean $\pm \mathrm{sd}$. P-value was obtained from Independent samples t-test.

Abbreviations: ADF: Alternate Day Fasting; CR: Calorie restriction; BMI: Body Mass Index, F: Female, M: Male.

\section{Secondary outcomes}

Compared to the CR diet, following the ADF diet led to a larger, significant, reduction in hs-CRP concentrations $(\mathrm{mg} / \mathrm{l})(-2.06 \pm 1.18$ vs $-0.97 \pm 0.82 ; \mathrm{P}=0.03)$. However, we did not detect any significant change in either TNF- $\alpha$ $(\mathrm{pg} / \mathrm{ml})(-3.47 \pm 5.77 \mathrm{vs}-2.21 \pm 5.04 ; \mathrm{P}=0.60)$ or IL-6 $(\mathrm{pg} / \mathrm{ml})(-1.08 \pm 2.70$ vs $-0.61 \pm 2.82 ; \mathrm{P}=0.49)$ between groups (Table 3).

Adherence to ADF diet resulted in a significant increase in PT (s) $(1.41 \pm 2.34$ vs $-0.41 \pm 2.17 ; \mathrm{P}<0.001)$ and
Table 2. Macronutrient intake of study participants at baseline

\begin{tabular}{lccc}
\hline Variables & $\begin{array}{c}\text { ADF Diet group } \\
(\mathrm{N}=35)\end{array}$ & $\begin{array}{c}\text { CR group Diet } \\
(\mathrm{N}=34)\end{array}$ & P-value \\
\hline Energy (kcal/day) & $2456 \pm 286$ & $2391 \pm 316$ & 0.37 \\
Carbohydrate (g/day) & $376 \pm 67$ & $352 \pm 56$ & 0.10 \\
Protein (g/day) & $83.7 \pm 12.3$ & $87.3 \pm 12.8$ & 0.23 \\
Fat (g/day) & $71.5 \pm 10.3$ & $69.8 \pm 11.2$ & 0.51 \\
MUFA (g/day) & $21.7 \pm 5.8$ & $19.9 \pm 6.7$ & 0.23 \\
PUFA (g/day) & $18.4 \pm 8.2$ & $17.8 \pm 7.3$ & 0.74 \\
\hline
\end{tabular}

Abbreviations: ADF: Alternate Day Fasting; CR: Calorie restriction; MUFA: monounsaturated fatty acid; PUFA: polyunsaturated fatty acid. 
Change in body weight

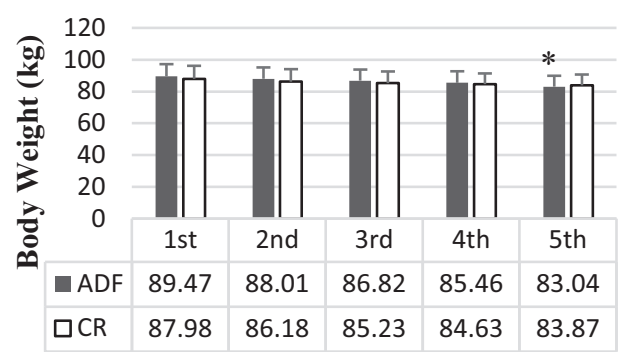

Change in waist circumstance

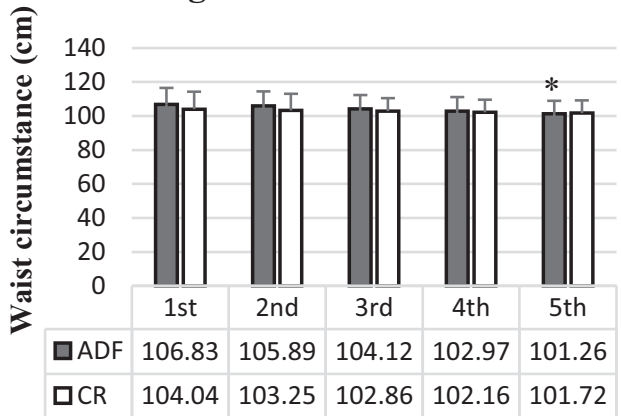

Change in BMI

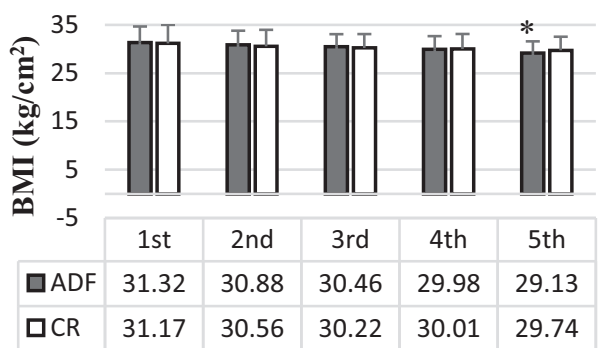

\section{Change in WHR}

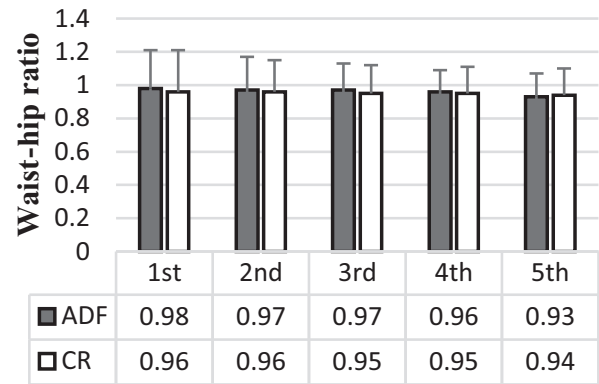

Figure 2. The changes in body weight, BMI, waist circumstance and waist-hip-ratio in alternate-day fasting diet (ADF; $N=38$ ) and calorie restriction (CR; $N=37$ ) groups during 4-months intervention. The results were obtained by repeated-measures ANOVA and figures are presented as mean $\pm \mathrm{sd}$. ${ }^{\star} \mathrm{P}<0.05$. Abbreviations: ADF: alternate day fasting diet; CR: calorie restriction; BMI: body mass index; WHR: waist-hip-ratio.

Table 3. Fat mass and Biochemical indexes at baseline and after 4-months intervention in subjects with metabolic syndrome

\begin{tabular}{|c|c|c|c|c|c|c|}
\hline Variables & Group & Baseline & End-of-trial & Changes & P-value* & P-value** \\
\hline Fat mass (kg) & $\begin{array}{l}\text { ADF } \\
C R\end{array}$ & $\begin{array}{l}37.1 \pm 9.25 \\
34.2 \pm 9.80\end{array}$ & $\begin{array}{l}31.2 \pm 6.15 \\
30.5 \pm 5.02\end{array}$ & $\begin{array}{l}-5.88 \pm 3.84 \\
-3.72 \pm 3.03\end{array}$ & $\begin{array}{c}0.001 \\
0.04\end{array}$ & 0.007 \\
\hline Fat free mass (kg) & $\begin{array}{l}\text { ADF } \\
C R\end{array}$ & $\begin{array}{l}52.3 \pm 8.67 \\
53.7 \pm 9.03\end{array}$ & $\begin{array}{l}51.8 \pm 7.12 \\
53.3 \pm 7.32\end{array}$ & $\begin{array}{l}-0.55 \pm 3.91 \\
-0.39 \pm 3.17\end{array}$ & $\begin{array}{l}0.59 \\
0.41\end{array}$ & 0.84 \\
\hline $\mathrm{Hs}-\mathrm{CRP}$ (mg/l) & $\begin{array}{l}\text { ADF } \\
C R\end{array}$ & $\begin{array}{l}4.27 \pm 1.95 \\
3.75 \pm 1.25\end{array}$ & $\begin{array}{l}2.21 \pm 2.61 \\
2.78 \pm 1.02\end{array}$ & $\begin{array}{l}-2.06 \pm 1.18 \\
-0.97 \pm 0.82\end{array}$ & $\begin{array}{l}<0.001 \\
0.001\end{array}$ & 0.03 \\
\hline $\mathrm{TNF}-\alpha(\mathrm{pg} / \mathrm{ml})$ & $\begin{array}{l}\text { ADF } \\
C R\end{array}$ & $\begin{array}{l}18.6 \pm 8.36 \\
17.2 \pm 7.38\end{array}$ & $\begin{array}{l}14.8 \pm 6.22 \\
16.4 \pm 5.69\end{array}$ & $\begin{array}{l}-3.47 \pm 5.77 \\
-2.21 \pm 5.04\end{array}$ & $\begin{array}{l}0.08 \\
0.09\end{array}$ & 0.60 \\
\hline IL-6 (pg/ml) & $\begin{array}{l}\text { ADF } \\
C R\end{array}$ & $\begin{array}{l}8.73 \pm 3.26 \\
7.47 \pm 2.10\end{array}$ & $\begin{array}{l}7.65 \pm 2.52 \\
6.86 \pm 2.96\end{array}$ & $\begin{array}{l}-1.08 \pm 2.70 \\
-0.61 \pm 2.82\end{array}$ & $\begin{array}{l}0.12 \\
0.38\end{array}$ & 0.49 \\
\hline PT (s) & $\begin{array}{l}\text { ADF } \\
C R\end{array}$ & $\begin{array}{l}12.7 \pm 1.67 \\
14.1 \pm 1.36\end{array}$ & $\begin{array}{l}14.1 \pm 2.01 \\
13.7 \pm 1.61\end{array}$ & $\begin{array}{c}1.41 \pm 2.34 \\
-0.41 \pm 2.17\end{array}$ & $\begin{array}{l}0.01 \\
0.35\end{array}$ & $<0.001$ \\
\hline a-PTT (s) & $\begin{array}{l}\text { ADF } \\
\text { CR }\end{array}$ & $\begin{array}{l}33.4 \pm 3.50 \\
34.4 \pm 2.90\end{array}$ & $\begin{array}{l}33.7 \pm 3.91 \\
32.6 \pm 3.73\end{array}$ & $\begin{array}{c}0.26 \pm 3.70 \\
-1.78 \pm 3.56\end{array}$ & $\begin{array}{l}0.71 \\
0.01\end{array}$ & 0.04 \\
\hline Fibrinogen (mg/dl) & $\begin{array}{l}\text { ADF } \\
C R\end{array}$ & $\begin{array}{l}264 \pm 53.6 \\
219 \pm 94.5\end{array}$ & $\begin{array}{l}230 \pm 69.1 \\
251 \pm 65.5\end{array}$ & $\begin{array}{c}-34.6 \pm 76.6 \\
32.3 \pm 94.3\end{array}$ & $\begin{array}{l}0.03 \\
0.10\end{array}$ & 0.08 \\
\hline
\end{tabular}

Vale reported as mean $\pm \mathrm{sd}$. *P-value was obtained from Paired t-test. **P-value was obtained from ANCOVA test adjusted by age, sex and baseline BMI. Abbreviations: ADF: Alternate day fasting; CR: Calorie restriction; hs-CRP: high-Sensitivity C-reactive protein; IL-6: interleukin-6; TNF- $\alpha$ : tumor necrosis factor- $\alpha$; PT: Prothrombin time, a-PTT: activated limited thromboplastin time.

a-PTT (s) (0.26 \pm 3.70 vs $-1.78 \pm 3.56 ; \mathrm{P}=0.04)$ time. Furthermore, a trend to significant reduction Fibrinogen levels $(\mathrm{mg} / \mathrm{dl})(-34.57 \pm 76.63$ vs $32.28 \pm 94.39 ; \mathrm{P}=0.08)$ was observed after ADF diet intervention in compare with CR diet (Table 3).

\section{Discussion}

Present study demonstrated that following the ADF diet for 4 months among patients with MetS had a beneficial effect on body weight, BMI, fat mass, WC, WHR, hs-CRP, PT, 
a-PTT levels in comparison to a CR diet, but did not affect fat free mass, TNF- $\alpha$ and IL-6 levels. Also, a trend towards significant reduction in fibrinogen levels was observed after $\mathrm{ADF}$ diet intervention in comparison to the CR diet.

Obesity is regarded as one of the principal risk factors in the development and progression of MetS [17]. Our study revealed that although both diets (ADF and CR) can lead to weight loss, as well as decrements in WC and fat mass (but not in fat free mass) after 4 months; however, the effect of the ADF diet on weight loss was greater than the CR diet. These findings were in accordance with some previous studies. For instance, Johnson et al. [18] reported that $\mathrm{ADF}$ diet administration resulted in $4 \mathrm{~kg}$ weight loss after 4 weeks in overweight individuals with moderate asthma (18). Similar results were also reported in studies using an $\mathrm{ADF}$ diet intervention on healthy overweight and obese adults; where it was reported that longer ADF administration may result in greater weight loss, and the authors suggested that the ADF diet can be a viable dietary option to help obese individuals lose, and manage, weight $[19,20]$.

Energy balance plays a mitigating role in body weight management, and weight loss correlates with a reduction in the total energy intake [21, 22]. Although the primary reason for greater weight loss in the ADF group may be attributed to a difference in total energy intake per week, participants in ADF group reported that they experienced lower appetite than before the intervention. It is conceivable that a change in appetite regulating hormones may have influenced our results. In animal models, it was reported that treatment with ADF can increase adiponectin concentrations, whilst decreasing resistin and leptin [23, 24]. However, in this study, we did not assess appetite related hormones and this effect was only reported anecdotally by patients, necessitating further studies which specifically examine the effect of ADF on appetite.

Another notable benefit of ADF vs CR for weight loss is the comparative ease in adherence. In conventional CR regimens, food consumption must be limited every day $[25,26]$, however, ADF diet require energy restriction only every other day which enhances adherence to dietary restriction protocols [27]. Also, in our study, the participants reported that ADF was comfortable to follow for an extended period. As weight loss is directly related to degree of dietary adherence [28], the high compliance rate to the $\mathrm{ADF}$ regimen plays a pivotal role in the total weight loss achieved.

The findings of the present study indicated that following an ADF diet results in a greater reduction in fat mass and waist circumstance when compared to CR. Although several studies have shown that CR can decrease visceral fat mass, this reduction is caused by decreasing overall body fat loss [29-31]. However, the ADF can elicit a pronounced visceral fat mass reduction, which makes it an efficacious option in the management of abdominal obesity. Previous studies have also reported results in accordance with our findings; for example, Varady et al., [23] showed that 4-weeks adherence to ADF can decrease visceral fat and redistribute fat to subcutaneous compartments. Bhutani et al., [32] reported a favorable effect of 8-weeks ADF on obesity treatment, where body weight, waist circumference and fat mass was markedly decreased. Moreover, Varady et al. [33] also showed that following an ADF diet resulted in a reduction of $3.6 \pm 0.7 \mathrm{~kg}$ of fat mass among normal and overweight subjects after 8 weeks. Because visceral fat mass and WC are strongly associated with insulin resistance, one of the main causes of MetS, ADF may be a promising alternative strategy for improvement and management of MetS.

Inflammation is a critical risk factor for several chronic diseases. In the present study, although a significant reduction in hs-CRP was observed after following ADF as compared to the CR diet, no significant change was found in TNF- $\alpha$ and IL- 6 between groups. In contrast with present study, Moro et al. [34] showed that eight weeks of timerestricted feeding can reduce TNF- $\alpha$ and IL- 6 compared to normal diet. In this study which was conducted on thirty-four resistance-trained males, the participants in time-restricted feeding group received $100 \%$ of their energy during 8 hours and fasted for remaining 16 hours of each day. This discrepancy between our results in these inflammatory factors and Moro et al. [34] study might be due to the difference between protocol of fasting diet. Unlike our study, the participants fasted every day in Moro et al. [34] study, therefore, it is reasonable that we expected more beneficial effect on metabolic markers such as inflammatory factors. On the other hand, the recruited subjects in Moro et al. [34] study was also different from us (resistance-trained male vs Met) which might be resulted from the difference between findings.

Animal studies [35-37] have previously reported that ADF can improve inflammation by suppressing gene expression of inflammatory factors including TNF- $\alpha$ and IL-1 $\beta$. Further suggesting that ADF may reduce the expression of nuclear NF-kB proteins which modulates the transcription of pro-inflammatory cytokines, acute phase proteins and chemokines such as interleukins, serum amyloid A, CRP and TNF- $\alpha$ [38]. It is also suggested that intermittent fasting results in activation of stress-induced pathway and enhances the generation of special proteins, where their transcription is induced in stressful conditions, including heat shock protein (HSP) 70 [39]. HSP 70 generally increases in response to severe conditions such as energy depletion, protein degradation and oxidative stress $[40,41]$. In addition to attach to unfolded or misfolded proteins to help refold protein and ensure normal configurations, HSP 70 exerts anti-inflammatory and anti-apoptosis 
activities [42]. In addition, a decrease in fat mass can facilitate a reduction in CRP levels [43], which seems to be the mechanism for $\mathrm{CRP}$ reduction in the $\mathrm{ADF}$ group in our study.

Fibrinogen is a putative inflammatory factor which is involved in acute phase reaction and tend to be higher in obese individuals than people with normal weight [44]. In the present study, the fibrinogen levels significantly decreased in ADF group and increased in CR group, however, this difference was not statistically significant between two groups. PT and a-PTT was increased in ADF group and decreased in CR group, and these changes were statistically different between two groups. Only limited information has been reported regarding the impact of dietary intervention on coagulation factors. Some studies have reported that reductions in fibrinogen are correlated with decreasing in fat mass [45]. Fibrinogen is an acute phase protein and its effect may change depending on the host factors [46]. It is possible that inflammatory mechanisms are involved in postprandial coagulation activation. So, ADF and CR diets both may be able to influence postprandial coagulation activation. However, the result from various reports are inconsistent and a precise reason for changes in fibrinogen, PT and a-PTT remains unclear. Further studies are required to clarify the possible relationship between adherence to a weight loss inducing diet and coagulation factors.

To the best of our knowledge, the present study was the first to investigate the effect of an ADF vs CR diet on body weight, inflammation and coagulation factors. However, there are several limitations that should be considered. First, due to the nature of dietary intervention studies, we could not perform trial in blinded fashion. Second, the sample size and duration of intervention was relatively short. However, even in this short period, we could show the prominent beneficial effects of ADF on MetS. Third, the compliance with diet by participants was determined through self-reporting, which might have resulted in misstatements; however, in order to reduce this bias, we endeavored to monitor participants via phone interviews throughout intervention, and completion of a 3-day food record.

\section{Conclusion}

Present study suggests that ADF is a more efficacious strategy in managing body weight, fat mass and waist circumstance in individuals with MetS. In addition, we demonstrate that a benefit of ADF is the ability to elicit decreases in hs-CRP, and improvements in PT and a-PTT, compared to a CR diet. These findings provide better insight into the capability of ADF vs CR for weight loss and management. However, further work is needed to generalize the findings to other populations with different health conditions, especially in nutrient deficient, at-risk individuals. Moreover, future studies are needed to investigate the long-term effect of ADF on metabolism, nutrient absorption and on holistic health.

\section{Electronic supplementary material}

The electronic supplementary material is available with the online version of the article at https://doi.org/ 10.1024/0300-9831/a000623

ESM 1. The weekly schedule of dietary following (Table E1).

\section{References}

1. Javandoost A, Afshari A, Saberi-Karimian M, Sahebkar A, Safarian H, Moammeri M, et al. The effects of curcumin and a modified curcumin formulation on serum Cholesteryl Ester Transfer Protein concentrations in patients with metabolic syndrome: A randomized, placebo-controlled clinical trial. Avicenna J Phytomed. 2018;8(4):330-7.

2. Kaur J. A comprehensive review on metabolic syndrome. Cardiol Res Pract. 2014;2014:943162. doi: 10.1155/2014/ 943162. Epub 2014 Mar 11.

3. Grundy SM. Metabolic syndrome update. Trends Cardiovasc Med. 2016;26(4):364-73.

4. Lam DW, LeRoith D. Metabolic Syndrome. In: De Groot LJ, Chrousos G, Dungan K, Feingold KR, Grossman A, Hershman $J M$, et al. editors. Endotext. South Dartmouth (MA): MDText.com, Inc.; 2000.

5. Esmaillzadeh A, Mirmiran P, Azadbakht L, Etemadi A, Azizi F. High prevalence of the metabolic syndrome in Iranian adolescents. Obesity (Silver Spring, Md). 2006;14(3):377-82.

6. Hoddy KK, Bhutani S, Phillips SA, Varady KA. Effects of different degrees of insulin resistance on endothelial function in obese adults undergoing alternate day fasting. Nutr Healthy Aging. 2016;4(1):63-71.

7. Chae JS, Paik JK, Kang R, Kim M, Choi Y, Lee S-H, et al. Mild weight loss reduces inflammatory cytokines, leukocyte count, and oxidative stress in overweight and moderately obese participants treated for 3 years with dietary modification. Nutr Res. 2013;33(3):195-203.

8. Musaad S, Haynes EN. Biomarkers of obesity and subsequent cardiovascular events. Epidemiol Rev. 2007;29(1):98-114.

9. Gu L, Liu W, Yan Y, Su L, Wu G, Liang B, et al. Influence of the beta-fibrinogen-455G/A polymorphism on development of ischemic stroke and coronary heart disease. Thromb Res. 2014:133(6):993-1005.

10. Eshghinia S, Mohammadzadeh F. The effects of modified alternate-day fasting diet on weight loss and CAD risk factors in overweight and obese women. J Diabetes Metab Disord. 2013;12(1):4.

11. Del Corral P, Chandler-Laney PC, Casazza K, Gower BA, Hunter GR. Effect of dietary adherence with or without exercise on weight loss: a mechanistic approach to a global problem. J Clin Endocrinol Metab. 2009;94(5):1602-7. 
12. Varady KA. Intermittent versus daily calorie restriction: which diet regimen is more effective for weight loss? Obesity reviews: an official journal of the International Association for the Study of Obesity. 2011;12(7):e593-601.

13. Varady KA, Bhutani S, Klempel MC, Kroeger CM, Trepanowski JF, Haus JM, et al. Alternate day fasting for weight loss in normal weight and overweight subjects: a randomized controlled trial. Nutr J. 2013;12(1):146.

14. Schulz KF, Altman DG, Moher D. CONSORT 2010 statement: updated guidelines for reporting parallel group randomised trials. BMC medicine. 2010;8(1):18.

15. Rezaianzadeh A, Namayandeh SM, Sadr SM. National Cholesterol Education Program Adult Treatment Panel III Versus International Diabetic Federation Definition of Metabolic Syndrome, Which One is Associated with Diabetes Mellitus and Coronary Artery Disease? Int J Prev Med. 2012;3(8): $552-8$.

16. Mifflin MD, St Jeor ST, Hill LA, Scott BJ, Daugherty SA, Koh YO. A new predictive equation for resting energy expenditure in healthy individuals. Am J Clin Nutr. 1990;51(2):241-7.

17. Després J-P, Lemieux I. Abdominal obesity and metabolic syndrome. Nature. 2006;444(7121):881.

18. Johnson JB, Summer W, Cutler RG, Martin B, Hyun D-H, Dixit $V D$, et al. Alternate day calorie restriction improves clinical findings and reduces markers of oxidative stress and inflammation in overweight adults with moderate asthma. Free Radic Biol Med. 2007;42(5):665-74.

19. Varady KA, Bhutani S, Church EC, Klempel MC. Short-term modified alternate-day fasting: a novel dietary strategy for weight loss and cardioprotection in obese adults. Am J Clin Nutr. 2009;90(5):1138-43.

20. Eshghinia S, Mohammadzadeh F. The effects of modified alternate-day fasting diet on weight loss and CAD risk factors in overweight and obese women. J Diabetes Metab Disord. 2013;12(1):4.

21. Al-Numair K. Body weight and some biochemical changes associated with Ramadan fasting in healthy Saudi men. J Med Sci. 2006;6(1):112-6.

22. Shariatpanahi ZV, Shariatpanahi MV, Shahbazi S, Hossaini A, Abadi A. Effect of Ramadan fasting on some indices of insulin resistance and components of the metabolic syndrome in healthy male adults. Br J Nutr. 2008;100(1):147-51.

23. Varady KA, Hudak CS, Hellerstein MK. Modified alternate-day fasting and cardioprotection: relation to adipose tissue dynamics and dietary fat intake. Metabolism. 2009;58(6): 803-11.

24. Varady KA, Allister CA, Roohk DJ, Hellerstein MK. Improvements in body fat distribution and circulating adiponectin by alternate-day fasting versus calorie restriction. J Nutr Biochem. 2010;21(3):188-95.

25. Malik VS, Hu FB. Popular weight-loss diets: from evidence to practice. Nat Clin Pract Cardiovasc Med. 2007;4(1):34-41.

26. Das SK, Gilhooly CH, Golden JK, Pittas AG, Fuss PJ, Cheatham RA, et al. Long-term effects of 2 energy-restricted diets differing in glycemic load on dietary adherence, body composition, and metabolism in CALERIE: a 1-y randomized controlled trial. Am J Clin Nutr. 2007;85(4):1023-30.

27. Varady KA, Hellerstein MK. Alternate-day fasting and chronic disease prevention: a review of human and animal trials. Am J Clin Nutr. 2007;86(1):7-13.

28. Church EC, Klempel MC, Bhutani S, Varady KA. Short-term modified alternate-day fasting: a novel dietary strategy for weight loss and cardioprotection in obese adults. Am J Clin Nutr. 2009;90(5):1138-43.

29. Weiss EP, Holloszy JO. Improvements in body composition, glucose tolerance, and insulin action induced by increasing energy expenditure or decreasing energy intake. J Nutr. 2007;137(4):1087-90.

30. Redman LM, Heilbronn LK, Martin CK, Alfonso A, Smith SR, Ravussin E, et al. Effect of calorie restriction with or without exercise on body composition and fat distribution. J Clin Endocrinol Metab. 2007;92(3):865-72.

31. Escrivá F, Gavete MLa, Fermín Yn, Pérez C, Gallardo N, Alvarez $\mathrm{C}$, et al. Effect of age and moderate food restriction on insulin sensitivity in Wistar rats: role of adiposity. J Endocrinol. 2007;194(1):131-41.

32. Bhutani S, Klempel MC, Berger RA, Varady KA. Improvements in coronary heart disease risk indicators by alternate-day fasting involve adipose tissue modulations. Obesity. 2010;18 (11):2152-9.

33. Varady KA, Bhutani S, Klempel MC, Kroeger CM, Trepanowski $J F$, Haus JM, et al. Alternate day fasting for weight loss in normal weight and overweight subjects: a randomized controlled trial. Nutr J. 2013;12(1):146.

34. Moro T, Tinsley G, Bianco A, Marcolin G, Pacelli QF, Battaglia $G$, et al. Effects of eight weeks of time-restricted feeding (16/ 8) on basal metabolism, maximal strength, body composition, inflammation, and cardiovascular risk factors in resistancetrained males. J Transl Med. 2016;14(1):290.

35. Yang W, Cao M, Mao X, Wei X, Li X, Chen G, et al. Alternate-day fasting protects the livers of mice against high-fat dietinduced inflammation associated with the suppression of Toll-like receptor 4/nuclear factor $\kappa B$ signaling. Nutr Res. 2016;36(6):586-93.

36. Castello L, Froio T, Maina M, Cavallini G, Biasi F, Leonarduzzi $G$, et al. Alternate-day fasting protects the rat heart against age-induced inflammation and fibrosis by inhibiting oxidative damage and NF-kB activation. Free Radic Biol Med. 2010;48 (1):47-54.

37. Vasconcelos AR, Yshii LM, Viel TA, Buck HS, Mattson MP, Scavone C, et al. Intermittent fasting attenuates lipopolysaccharide-induced neuroinflammation and memory impairment. J Neuroinflammation. 2014;11(1):85.

38. Krakauer T. Molecular therapeutic targets in inflammation: cyclooxygenase and NF-кB. Curr Drug Targets Inflamm Allergy. 2004;3(3):317-24.

39. Adrie C, Richter C, Bachelet M, Banzet N, François D, DinhXuan AT, et al. Contrasting effects of NO and peroxynitrites on HSP70 expression and apoptosis in human monocytes. Am J Physiol Cell Physiol. 2000;279(2):C452-C60.

40. Guttman SD, Glover CV, Allis CD, Gorovsky MA. Heat shock, deciliation and release from anoxia induce the synthesis of the same set of polypeptides in starved T. pyriformis. Cell. 1980;22(1):299-307.

41. Morton JP, Kayani AC, McArdle A, Drust B. The exerciseinduced stress response of skeletal muscle, with specific emphasis on humans. Sports Med. 2009;39(8):643-62.

42. Golbidi S, Daiber A, Korac B, Li H, Essop MF, Laher I. Health benefits of fasting and caloric restriction. Curr Diab Rep. 2017;17(12):123.

43. Hakeam HA, O'Regan PJ, Salem AM, Bamehriz FY, Jomaa LF. Inhibition of C-reactive protein in morbidly obese patients after laparoscopic sleeve gastrectomy. Obes Surg. 2009; 19(4):456-60.

44. Aziz CB, Omar N, Abdullah WZ, Jalil RA, Nik WS, Zakaria R. Reduced fibrinogen, fibrinolytic biomarkers, and physical parameters after a weight-loss program in obese subjects. N Am J Med Sci. 2014 Aug;6(8):377-82.

45. Belza A, Toubro S, Stender S, Astrup A. Effect of diet-induced energy deficit and body fat reduction on high-sensitive CRP and other inflammatory markers in obese subjects. Int $J$ Obes. 2009;33(4):456. 
46. Bladbjerg E-M, Larsen TM, Due A, Jespersen J, Stender S, Astrup A. Postprandial coagulation activation in overweight individuals after weight loss: acute and long-term effects of a high-monounsaturated fat diet and a low-fat diet. Thromb Res. 2014;133(3):327-33.

\section{History}

Received June 14, 2019

Accepted October 18, 2019

Published online January 31, 2020

\section{Acknowledgements}

The authors would like to thank all the study participants. They are also grateful to the all staff for their support and cooperation.

\section{Conflict of interest}

The authors declare that there are no conflicts of interest.

\section{Funding}

This research did not receive any specific grant from funding agencies in the public, commercial, or not-for-profit sectors.

\section{Sayyed Morteza Safavi}

Department of Clinical Nutrition

School of Nutrition and Food Science

Isfahan University of Medical Science

Isfahan

Iran

safavimorteza@yahoo.com 